\title{
ENERGIZATION OF IONOSPHERIC IONS BY ELECTROSTATIC HYDROGEN CYCLOTRON WAVES
}

\author{
Nagendra Singh, R. W. Schunk and J. J. Sojka
}

Center for Atmospheric and Space Sciences, Utah State University, Logan, Utah 84322

Abstract. Interactions between ionospheric ions and a monochromatic electrostatic hydrogen cyclotron wave were studied numerically for conditions corresponding to the auroral plasma. Strong heating of the minority ions $\mathrm{He}^{+}, \mathrm{He}^{++}$, and $\mathrm{O}^{+}$ were observed. The fraction of the initial ion population which underwent heating was found to strongly depend on the mass, charge, and initial temperature of the ion species.

\section{Stochastic Acceleration}

The energization of the low energy ionospheric ions flowing along geomagnetic field lines to high altitudes is one of the fundamental problems in magnetospheric physics. In recent years it has been suggested that these ions are energized by electrostatic hydrogen-cyclotron (EHC) waves excited above the topside ionosphere in the auroral region by the field-aligned currents [Kindel and Kennel, 1972; Kintner and Kelley, 1978; Kintner et al, 1979; Ungstrup et al, 1979; Klumpar, 1979; Lysak et al, 1980]. Lysak et al considered the formation of energetic proton tails by the interaction of $\mathrm{EHC}$ waves and protons. In fusion research plasma heating by coherent waves is getting considerable attention; it is now well established that the interaction of charge particles with coherent waves of large enough amplitudes can heat the plasma particles [Smith and Kaufman, 1978; Fakuyama et al, 1977; Karney, 1972; Abe et al, 1980]. Recently, Papadopoulos et al [1980] applied the results of Karney to ionospheric ions to predict a very large heating for $\mathrm{O}^{+}$ ions and a relatively moderate heating of $\mathrm{He}^{+}$ions by an EHC wave. The purpose of this letter is to present a summary of a detailed investigation in which interactions of several types of ions with EHC waves were studied numerically. Our results show an appreciably larger heating for helium ions than predicted by Papadopolous et al. Furthermore, our studies indicate what portion of the initial cold population undergoes heating, and hence, whether the heating occurs in the bulk or in the tail of the initial distribution. We discuss heating of $\mathrm{O}^{+}$, $\mathrm{He}^{+}$, and $\mathrm{He}^{++}$ions.

In order to study the interactions between ions and EHC waves, we numerically solved the following ion equations of motion:

$$
\begin{gathered}
\dot{\mathrm{V}}_{\mathrm{x}}=\left(\mathrm{q}_{\mathrm{i}} / \mathrm{M}_{\mathrm{i}}\right) \mathrm{E}_{\mathrm{x}}+\mathrm{V}_{\mathrm{y}} \Omega_{\mathrm{i}}, \quad \dot{\mathrm{x}}=\mathrm{V}_{\mathrm{x}} \\
\dot{\mathrm{V}}_{\|}=\left(\mathrm{q}_{\mathrm{i}} / \mathrm{M}_{\mathrm{i}}\right) \mathrm{E}_{\|}, \dot{\mathrm{z}}=\mathrm{V}_{\|} \\
\mathrm{V}_{\mathrm{y}}+\Omega_{\mathrm{i}} \mathrm{x}=\mathrm{C}
\end{gathered}
$$

where $V_{x}, V_{y}$ and $V_{\|}$are the components of the velocity vector $\mathrm{V}$ along the $\mathrm{x}, \mathrm{y}$ and $\mathrm{z}$ directions. The magnetic field $\underline{B}_{0}$ is assumed to be along the $\mathrm{z}$ axis; $\Omega_{\mathrm{i}}$ is the cyclotron frequency of an ion of mass $M_{i}$ and charge $q_{i}$; and $C$ is a constant determined by the initial condition for the ions at $t=0$. The electric field components $\mathrm{E}_{\mathrm{x}}$ and $\mathrm{E}_{\|}$of the wave are obtained from the potential

$$
\Phi(\mathrm{x}, \mathrm{z}, \mathrm{t})=\Phi_{\mathrm{o}} \operatorname{COS}\left(\mathrm{k}_{\perp} \mathrm{x}+\mathrm{k}_{\|} \mathrm{z}-\omega \mathrm{t}\right)
$$

where $k_{\perp}$ and $k_{\|}$are the wave vectors along the $x$ and $z$ axes, and $\Phi_{0}$ and $\omega$ are the amplitude and frequency of the EHC wave, respectively.

The set of equations (1) and (2) were solved for a given number Copyright 1981 by the American Geophysical Union. of particles which were initially Maxwellian distributed with a prescribed temperature. The solutions were advanced in time by the standard time-centered leap-frog method. A great care was exercised in choosing the time step for each ion species so that numerical errors were minimized. The wave parameters used in our calculations were

$$
\begin{gathered}
\hat{\mathbf{k}}_{\perp}=\mathrm{k}_{\perp} \mathrm{r}_{\mathrm{H}}=1.7, \quad \omega=1.2 \Omega_{\mathrm{H}}, \\
\hat{\Phi}_{\mathrm{o}}=\mathrm{e} \Phi_{0} / \mathrm{k}_{\mathrm{B}} \mathrm{T}_{\mathrm{H}}=0.4, \quad \mathrm{k}_{\mathrm{II}}=\mathrm{k}_{\perp} / 6
\end{gathered}
$$

where $r_{H}, \Omega_{H}$ and $T_{H}$ are the Larmor radius, cyclotron frequency, and temperature of hydrogen ions, respectively. In most of our numerical studies, 2000 particles were used. However, for selected cases we considered 10,000 particles and obtained essentially the same statistics. The minority ions were initially characterized by a Maxwellian temperature which was varied from $\mathrm{T}_{\mathrm{H}} / 10$ to $10 \mathrm{~T}_{\mathrm{H}}$. Such a temperature variation is expected in the topside polar ionosphere based on both experimental and theoretical grounds (Maier and Hoffman, 1974; Holzer et al, 1971; Raitt et al, 1975, 1977, 1978).

The parameters given by equation (3) are the same as those used by Papadopoulos et al (1980), except for the value of $\mathbf{k}_{\|}$. These authors assumed a purely perpendicular propagation for the EHC wave. However, from the theoretical study of Kindel and Kennel (1971) it appears that the ratio of $k_{1} / k_{\|}$varies between 5 and 10 as the proton to electron temperature ratio ranges from very large values to unity.

Several theoretical studies have been conducted which predict stochastic heating of charge particles in a coherent (nonstochastic) wave propagating in a nearly perpendicular direction to the magnetic field when the wave amplitude exceeds a threshold (Fakuyama et al, 1977; Karney, 1978; Abe et al, 1980);

$$
\delta=n \alpha\left|J_{n}\left(\xi_{\text {pn }}\right)\right| / \xi_{\text {pn }} \geq \delta_{\text {th }}, p=1,2,3,4 \ldots \ldots
$$

where the threshold value $\delta_{\text {th }}$ ranges from 0.15 to 0.25 . We will use the value $\delta_{\text {th }} \approx 0.25$, as reported by Karney (1978). The quantity $\alpha$ contains the wave amplitude:

$$
\begin{array}{r}
\alpha=\mathbf{k}_{\perp}^{2} \mathbf{q} \Phi_{\mathrm{o}} / \mathrm{M}_{\mathrm{i}} \Omega_{\mathrm{i}}{ }^{2} \\
=\hat{\mathbf{k}}_{\perp}^{2} \hat{\Phi}_{\mathrm{o}}(\mathrm{e} / \mathrm{q}) \mathrm{M}_{\mathrm{i}} / \mathrm{M}_{\mathrm{H}}
\end{array}
$$

where $\mathrm{M}_{\mathrm{H}}$ is the mass of a proton.

The order $n$ of the Bessel function $J_{n}\left(\xi_{p n}\right)$ is an integer close to $\omega / \Omega_{\mathrm{i}}$. The argument $\xi_{\mathrm{pn}}$ is determined by $\left[\mathrm{d} J_{\mathrm{n}}(\xi) / \mathrm{d} \xi\right]_{\xi}=\xi_{\mathrm{p}}=0$. Note that $\xi=k_{\perp} r_{i}$, where $r_{i}$ is the Larmor radius of the ion. The maxima of $\left|J_{n}(\xi)\right|$ are separated by its zeros. We define the range of $\xi$, separated by the zeros, as cells [Abe et al., 1980]. The index $\mathrm{p}$ on $\xi$ indicates the cell number beginning with the lowest cell.

Since as $\xi_{\mathrm{pn}}$ increases $\left|J_{n}\left(\xi_{\mathrm{pn}}\right)\right|$ decreases, for a given amplitude condition (4) is met only over a limited number of cells. In terms of energization of ions, it implies that the acceleration of ions is continued until the ion Larmor radius enters the cell in which (4) is no longer satisfied. Table 1 shows the values of $\delta$ over several cells for $\Phi_{0}=0.4$ and for $\mathrm{He}^{++}$and $\mathrm{He}^{+}$. For $\mathrm{O}^{+}, \alpha \sim 18.5$ and thus the threshold criterion is satisfied over a very large number of cells (not shown in Table 1).

When the wave amplitude is large enough, causing heating to extend to a large cell number, the Bessel function can be re- 
Table 1. Values of $\delta$ for $\mathrm{He}^{+}$and $\mathrm{He}^{++}$.

\begin{tabular}{lcccccc}
\hline IONS & CELL NO. & 1 & 2 & \multicolumn{1}{c}{3} & \multicolumn{1}{c}{4} & \multicolumn{1}{c}{5} \\
\hline $\mathrm{He}^{+}$ & $\delta(n=4)$ & 1.36 & 0.54 & 0.33 & 0.23 & 0.177 \\
$\alpha=4.62$ & $\delta(n=5)$ & 1.35 & 0.56 & 0.36 & 0.247 & 0.18 \\
\hline $\mathrm{He}^{++}$ & $\delta(n=2)$ & 0.72 & 0.22 & 0.1 & 0.076 & \\
$\alpha=2.3$ & $\delta(n=3)$ & 0.71 & 0.248 & 0.15 & 0.1 & \\
\hline
\end{tabular}

placed by its asymptotic representation and an estimate of the final heating can be obtained [Papadopoulos et al, 1980];

$$
\mathbf{k}_{\perp} \mathrm{r}_{\mathrm{f}}=(4 \mathrm{n} \alpha)^{2 / 3}(2 / \pi)^{1 / 3}
$$

where $r_{f}$ is the final Larmor radius of the ion after its heating. In terms of ion energy, $E_{f}=(1 / 2) M_{i} V_{\perp}^{2}$, (6) becomes

$$
\begin{gathered}
\mathrm{E}_{\mathrm{f}} \approx 3.2 \times\left(2 \hat{\mathrm{k}}_{\perp} / \pi\right)^{2 / 3}\left(\hat{\Phi}_{\mathrm{o}}\right)^{4 / 3}\left(\mathrm{M}_{\mathrm{i}} / \mathrm{M}_{\mathrm{H}}\right)^{5 / 3} \\
\cdot(\mathrm{e} / \mathrm{q})^{2 / 3} \mathrm{~T}_{\mathrm{H}}
\end{gathered}
$$

As pointed out by Papadopoulos et al (1980), (7) predicts a heating of $\mathrm{O}^{+}$by a factor of about $100 \mathrm{~T}_{\mathrm{H}}$ and of $\mathrm{He}^{+}$by $10 \mathrm{~T}_{\mathrm{H}}$. Our numerical calculations show that strictly speaking this prediction is valid for $\mathrm{O}^{+}$ions only when the initial $\mathrm{O}^{+}$ temperature satisfies the condition $T\left(O^{+}\right) \geq T_{\mathrm{H}}$. For other relatively lighter ions, such as $\mathrm{He}^{+}$and $\mathrm{He}^{++}$, heating in excess of (7) is obtained. We show below that the initial ion populations which undergo acceleration are very different from each other for $\mathrm{O}^{+}$on the one hand and $\mathrm{He}^{+}$and $\mathrm{He}^{++}$on the other.

\section{Acceleration of $\mathrm{O}^{+}$}

We just pointed out that $\mathrm{O}^{+}$ions are expected to gain a large energy owing to stochastic acceleration by the EHC wave. However, our calculations showed that a large heating takes place only when the initial $\mathrm{O}^{+}$temperature satisfies the condition $\mathrm{T}\left(\mathrm{O}^{+}\right) \geq \mathrm{T}_{\mathrm{H}}$. We did not observe acceleration when $\mathrm{T}\left(\mathrm{O}^{+}\right)=$ $T_{H} / 10$. Figures $1 a$ and $b$ show the heating when $T\left(O^{+}\right)=T_{H}$ and $\mathrm{T}\left(\mathrm{O}^{+}\right)=10 \mathrm{~T}_{\mathrm{H}}$, respectively. We have shown in these figures the $\mathrm{O}^{+}$velocity distribution function in the $\mathrm{V}_{\|}-\mathrm{V}_{\perp}$ plane, where the velocities are normalized with respect to $\mathrm{a}(\mathrm{i})=\left(2 \mathrm{k}_{\mathrm{B}} \mathrm{T}_{\mathrm{i}} / \mathrm{M}_{\mathrm{i}}\right)^{1 / 2}$ and where $T_{i}$ is the initial ion temperature. When $T\left(O^{+}\right)=T_{H}$, the heating leads to the formation of an energetic tail; the bulk
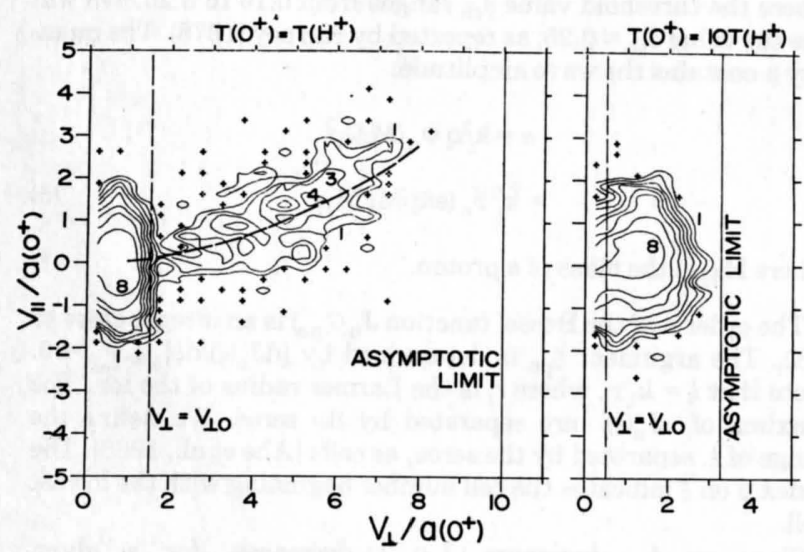

Figure 1. $\mathrm{O}^{+}$distribution in the $\mathrm{V}_{\|}-\mathrm{V}_{\perp}$ plane. The contours shown are for constant phase-space density $\mathrm{N}$. The numbers marked on the contours indicate the density in units of $\ln (N)=1 / 2$. The scattered points marked by + signs indicate very small densities $(\ln (\mathrm{N})<1 / 2)$ in those regions. (a) Distribution function for $\mathrm{T}\left(\mathrm{O}^{+}\right)=\mathrm{T}_{\mathrm{H}}$ showing the formation of an energetic tail. (b) Distribution function when initially $\mathrm{T}\left(\mathrm{O}^{+}\right)=10 \mathrm{~T}_{\mathrm{H}}$. In this case, bulk heating occurs. Broken vertical lines indicate the lower limit on the initial velocity for $\mathrm{O}^{+}$ions to undergo acceleration. The solid vertical lines indicate the asymptotic limit on the final acceleration. A speed distribution is plotted in the $V_{\perp}$ plane.

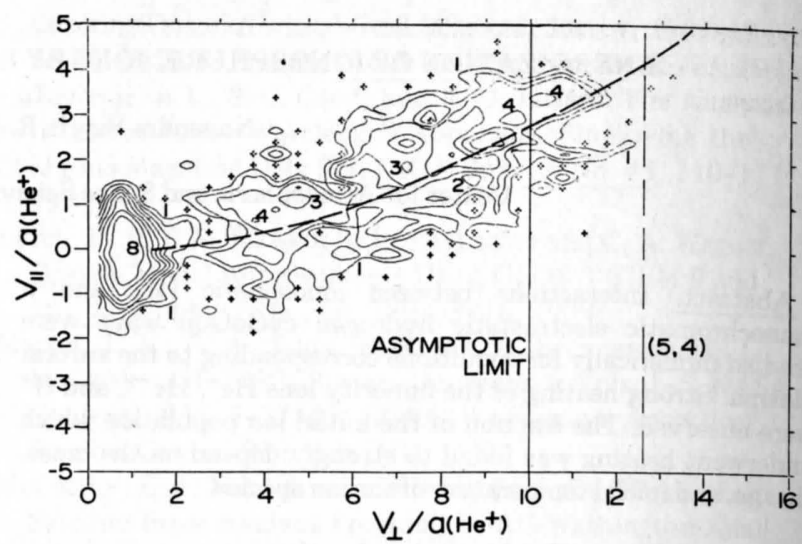

Figure 2. $\mathrm{He}^{+}$distribution function in the $\mathrm{V}_{1}-\mathrm{V}_{\perp}$ plane when initially $\mathrm{T}\left(\mathrm{He}^{+}\right) / \mathrm{T}_{\mathrm{H}}=0.1$. Acceleration leads to the formation of an energetic tail. The final heating goes beyond the asymptotic limit, $\mathrm{V}_{\perp}=$ $10 \mathrm{a}\left(\mathrm{He}^{+}\right)$, to the upper boundary of the fourth cell. The initial population of $\mathrm{He}^{+}$ions which undergo acceleration are shown in Figure 3. These ions fall within the cyclotron-resonance widths for $n=4$ and 5 .

of the distribution remains nearly unaffected. If we define the energetic tail by the criterion that any particle with $\mathrm{V}_{\perp}>2 \mathrm{a}\left(\mathrm{O}^{+}\right)$, is in the tail, then initially only $4 \%$ of the particles were in the tail region, while after a time interval of about $160 \tau\left(\mathrm{O}^{+}\right)$their number increased to $20 \%$. Note that by this time the heating has not reached the limit, as predicted by (7) and as shown in Figure 1a by the vertical line $\mathrm{V}_{\perp}=10 \mathrm{a}\left(\mathrm{O}^{+}\right)$.

When the $\mathrm{O}^{+}$ions were initially very hot $\left(\mathrm{T}\left(\mathrm{O}^{+}\right)=10 \mathrm{~T}_{\mathrm{H}}\right)$, the heating occured in the bulk (Fig. 1b), and in a time of about $160 \tau\left(\mathrm{O}^{+}\right)$it reached the limit indicated by the vertical line $\mathrm{V}_{1} \approx$ $3 \mathrm{a}\left(\mathrm{O}^{+}\right)$in Fig. $1 \mathrm{~b}$.

It should be noted that the above observations from the numerical calculations are in fairly good agreement with theoretical predictions [Karney, 1978]. Since for $\mathrm{O}^{+}, \Omega\left(\mathrm{O}^{+}\right) \ll \omega$, the ion motion in the presence of the wave occurs as though the ions are nearly unmagnetized. Therefore, the wave-particle in teraction progresses in the same fashion as in unmagnetized plasma. The stochastic acceleration occurs for the particles trapped by the wave. The minimum velocity for trapping is given by [Karney, 1978],

$$
\begin{aligned}
\mathrm{V}_{\perp \mathrm{o}} & \approx\left(\omega / \mathrm{k}_{\perp}\right)\left(1-\alpha^{1 / 2} / \mathrm{n}\right) \\
& \approx 0.4 \mathrm{a}\left(\mathrm{H}^{+}\right)
\end{aligned}
$$

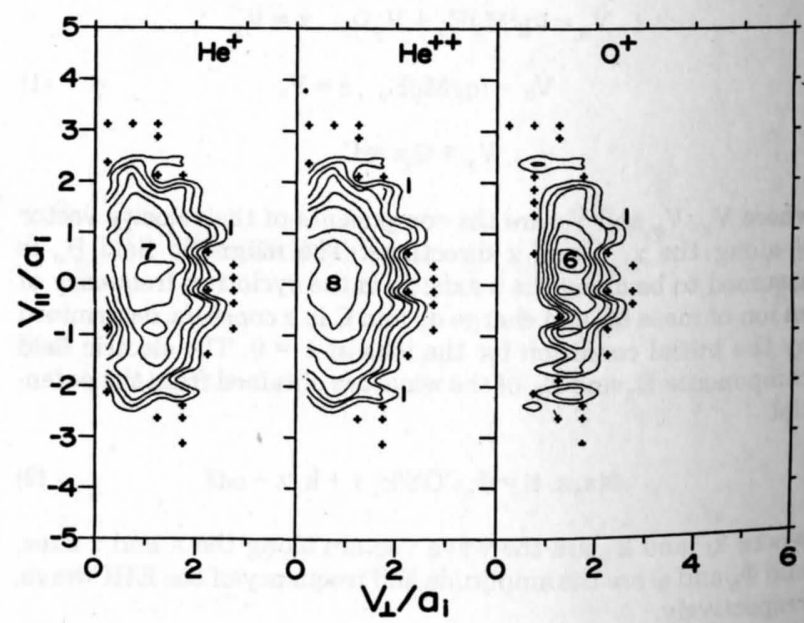

Figure 3. The initial population of ions that is subsequently accelerated by the EHC wave. The three panels correspond to the three cases that we considered. 
The broken vertical lines in Figures $1 \mathrm{a}$ and $\mathrm{b}$ show the lower limits on velocities required for $\mathrm{O}^{+}$ions to undergo acceleration, as determined by (8). This fact is clearly borne out by our numerical calculations (Fig. 1a); the contours of the distribution function for $\mathrm{V}_{\perp}<\mathrm{V}_{\perp}$ o remain nearly unaffected. Since for $\mathrm{T}\left(\mathrm{O}^{+}\right)$ $=\mathrm{T}_{\mathrm{H}}, \mathrm{V}_{\perp \mathrm{O}}$ falls in the tail region, only a relatively small number of particles are accelerated, forming an energetic tail. On the other hand, when $\mathrm{T}\left(\mathrm{O}^{+}\right)=10 \mathrm{~T}_{\mathrm{H}}, \mathrm{V}_{\perp \mathrm{o}}$ falls in the bulk and a large number of particles are accelerated, giving rise to a bulk heating.

When the $\mathrm{O}^{+}$ions are very cold $\left(\mathrm{T}\left(\mathrm{O}^{+}\right) \approx \mathrm{T}_{\mathrm{H}} / 10\right)$ the number of accelerated ions is negligibly small, since $\mathrm{V}_{\perp \mathrm{o}} \approx 5 \mathrm{a}\left(\mathrm{O}^{+}\right)$and because there are hardly any particles in a Maxwellian distribution beyond this velocity.

A noteworthy feature of the accelerated ions in Figure $1 \mathrm{a}$ is that they follow approximately a parabolic curve marked by the dotted line and described by the relation

$$
\Delta V_{\|}=\left(k_{\|} / 2 \omega\right) \Delta V_{\perp}^{2}, \quad \Delta V_{\perp}^{2} \gg q \Phi_{0} / M_{i}, \text { and } \omega / k_{\|} \gg V_{\|}
$$

where $\Delta V_{\|}$and $\Delta V_{\perp}$ are the increments in $V_{\|}$and $V_{\perp}$ due to the acceleration of a particle with initial $V_{\perp}=O$. This parabolic law for the acceleration follows from the constancy of the Hamiltonian in the wave frame (Smith and Kaufman, 1978). Thus, the ions are accelerated not only in the perpendicular direction, but in the parallel direction as well. However, the larger the parallel phase velocity the smaller the parallel acceleration.

\section{Acceleration of $\mathrm{He}^{+}$}

The acceleration of $\mathrm{He}^{+}$ions is shown in Figure 2, where the $\mathrm{He}^{+}$distribution function is plotted in the $\mathrm{V}_{\|}-\mathrm{V}_{\perp}$ plane. Note the formation of an energetic tail. By the time $\mathrm{t} \approx 300 \tau\left(\mathrm{He}^{+}\right)$, when acceleration is nearly stopped, the number of ions in the energetic tail $\left(\mathrm{V}_{\perp}>2 \mathrm{a}\left(\mathrm{He}^{+}\right)\right)$increased from $4 \%$ to $40 \%$. The vertical solid line $\mathrm{V}_{\perp} \approx 10 \mathrm{a}\left(\mathrm{He}^{+}\right)$shows the asymptotic limit on heating, as given by (7). Note that the heating goes beyond this limit. However, the limit on the heating is described very well by the fact that the threshold criterion (4) for $\mathrm{He}^{+}$is met until the fourth cell. The final heating is determined by the upper boundary of this cell, corresponding to $\xi=19$. This limit is also indicated in Figure 2 by the vertical line marked $(5,4)$, where 5 indicates $n=5$ cyclotron resonance and 4 indicates the cell number. The acceleration in the $V_{\|}=V_{\perp}$ plane is well described by the parabolic curve given by (9).

We found a characteristic difference between the acceleration of $\mathrm{O}^{+}$and $\mathrm{He}^{+}$; the difference lies in the portion of the initial distribution which undergoes acceleration. As discussed before, only those $\mathrm{O}^{+}$ions which have an initial perpendicular velocity $\mathrm{V}_{\perp}>\mathrm{V}_{\perp}$ o undergo acceleration (see Figure 3). On the other hand, the determining factor for $\mathrm{He}^{+}$is the cyclotron resonances given by

$$
\omega-\mathrm{n} \Omega_{\mathrm{i}}-\mathbf{k}_{\|} \mathrm{V}_{\|}=0
$$

We found that most of the $\mathrm{He}^{+}$ions which undergo acceleration initially come from the region of the $n=4$ and $n=5$ overlapping resonances. Table 2 shows the resonance velocities $V_{\| r}$ and the resonance half-widths, given by [Smith and Kaufman, 1978]

$$
\Delta \mathrm{V}_{\mathrm{I}}=\sqrt{2} \hat{\Phi}_{\mathrm{o}}^{1 / 2}\left|\mathrm{~J}_{\mathrm{n}}(\xi)\right|^{1 / 2} \mathrm{a}\left(\mathrm{H}^{+}\right)
$$

\begin{tabular}{|c|c|c|c|c|c|}
\hline \multicolumn{3}{|c|}{$\mathrm{He}^{+}$} & \multicolumn{3}{|c|}{$\mathrm{He}^{++}$} \\
\hline $\mathrm{n}$ & $\mathbf{V}_{\| \mathbf{r}}$ & $\Delta \mathrm{V}_{\|}$ & $\mathbf{n}$ & $\mathrm{V}_{\| \mathbf{r}}$ & $\Delta \mathrm{V}_{\|}$ \\
\hline 4 & $+0.5 \mathrm{a}\left(\mathrm{H}^{+}\right)$ & $0.56 \mathrm{a}\left(\mathrm{H}^{+}\right)$ & 2 & $0.5 \mathrm{a}\left(\mathrm{H}^{+}\right)$ & $0.6 \mathrm{a}\left(\mathrm{H}^{+}\right)$ \\
\hline 5 & $-0.125 \mathrm{a}\left(\mathrm{H}^{+}\right)$ & $0.55 \mathrm{a}\left(\mathrm{H}^{+}\right)$ & 3 & $-0.75 a\left(\mathrm{H}^{+}\right)$ & $0.56 \mathrm{a}\left(\mathrm{H}^{+}\right)$ \\
\hline
\end{tabular}

Table 2. Resonance velocities and half-widths in units of $\mathrm{H}^{+}$thermal speed.

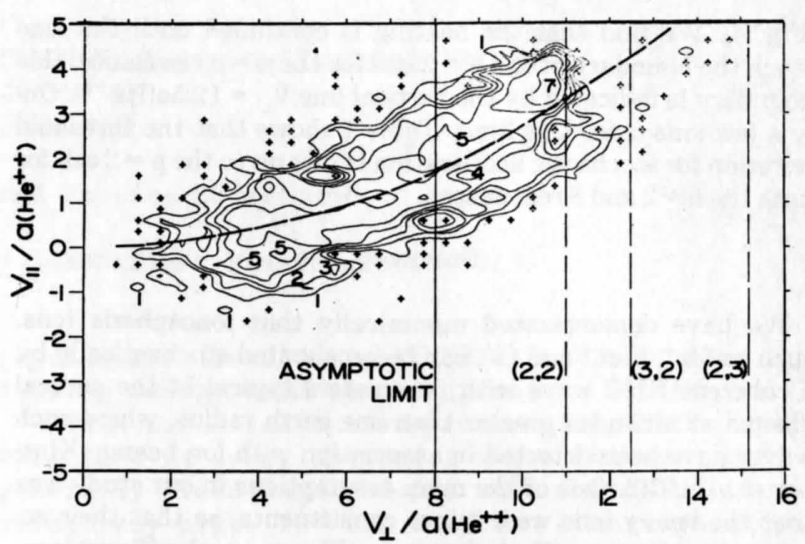

Figure 4. Distribution function for $\mathrm{He}^{++}$ions in the $\mathrm{V}_{\|}-\mathrm{V}_{\perp}$ plane. Note the disappearance of the bulk population. Heating goes beyond the asymptotic limit to the upper boundary of the second cell for the $n$ $=3$ resonance, as marked by the vertical line $(3,2)$. Upper boundaries of the second and third cells for the $\mathrm{n}=2$ resonance are also indicated.

The $\mathrm{He}^{+}$ions which undergo acceleration are shown in Figure 3. Out of a total of 925 accelerated ions, 625 initially come from the region of the overlapping resonances $-0.125 \leq \mathrm{V}_{\|} / \mathrm{a}\left(\mathrm{H}^{+}\right)$ $\leq 0.56 \mathrm{a}\left(\mathrm{H}^{+}\right)$.

The characteristic difference between the initial populations undergoing acceleration for $\mathrm{He}^{+}$and $\mathrm{O}^{+}$gives rise to different numbers for the accelerated ions. When $\mathrm{O}^{+}$is very cold $\left(\mathrm{T}\left(\mathrm{O}^{+}\right) / \mathrm{T}_{\mathrm{H}}=0.1\right)$, a negligible number of $\mathrm{O}^{+}$ions gets accelerated, while for a similar initial ratio of $\mathrm{T}\left(\mathrm{He}^{+}\right) / \mathrm{T}_{\mathrm{H}}$, the number of $\mathrm{He}^{+}$ions in the tail increases to $40 \%$ of the total population. Only when the initial $\mathrm{O}^{+}$temperature equals $\mathrm{T}_{\mathrm{H}}$ does the $\mathrm{O}^{+}$ energetic tail population increase to $20 \%$.

When the initial $\mathrm{He}^{+}$temperature equals $\mathrm{T}_{\mathrm{H}}$, the heating occurs in the bulk and the final $\mathrm{He}^{+}$temperature increases to about $10 \mathrm{~T}_{\mathrm{H}}$. When the initial $\mathrm{He}^{+}$temperature is further increased to $10 \mathrm{~T}_{\mathrm{H}}$, relatively very little heating is observed.

\section{Acceleration of $\mathrm{He}^{++}$}

Figure 4 shows the heating of $\mathrm{He}^{++}$ions for an initially cold population $\left(\mathrm{T}\left(\mathrm{He}^{++}\right)=\mathrm{T}_{\mathrm{H}} / 10\right)$. In this case the heating occurs very rapidly, and in a time interval of about $100 \mathrm{He}^{++}$cyclotron periods, the bulk population is nearly completely accelerated into the tail $\left(\mathrm{V}_{\perp}>2 \mathrm{a}\left(\mathrm{He}^{++}\right)\right.$) (Figure 3). As with $\mathrm{He}^{+}$, the acceleration affects the particles satisfying the cyclotron resonance conditions. Table 2 gives the resonance velocities and the width of the resonances for $\mathrm{n}=2$ and 3 . It turns out that ions with $\mathrm{V}_{\|}<0$ are resonant with $n=3$, while those with $V_{\|}>0$ are resonant with $\mathrm{n}=2$. These two resonances have sufficiently wide widths to accelerate the bulk population. The acceleration occurs along the parabolic resonance curve given by the dotted line in Figure 4.

The asymptotic limit on heating, as given by (7), is indicated in Figure 4 by the solid vertical line $V_{\perp} \approx 8 \mathrm{a}\left(\mathrm{He}^{++}\right)$. We note that the heating exceeds this limit by at least a factor of 2 , as there are an appreciable number of particles even at $V_{\perp} \approx 12 \mathrm{a}\left(\mathrm{He}^{++}\right)$

Table 3. Temperature Dependence of Heating for Different Ion Species.

$\begin{array}{ccc}\begin{array}{c}\mathrm{T}\left(\mathrm{O}^{+}\right)=\mathrm{T}_{\mathrm{H}} / 10 \\ \text { no heating }\end{array} & \begin{array}{c}\mathrm{T}\left(\mathrm{O}^{+}\right)=\mathrm{T}_{\mathrm{H}} \\ \text { tail }\end{array} & \begin{array}{c}\mathrm{T}\left(\mathrm{O}^{+}\right)=10 \mathrm{~T}_{\mathrm{H}} \\ \text { bulk }\end{array} \\ \begin{array}{c}\mathrm{T}\left(\mathrm{He}^{+}\right)=\mathrm{T}_{\mathrm{H}} / 10 \\ \text { tail }\end{array} & \begin{array}{c}\mathrm{T}\left(\mathrm{He}^{+}\right)=\mathrm{T}_{\mathrm{H}} \\ \text { bulk }\end{array} & \begin{array}{c}\mathrm{T}\left(\mathrm{He}^{+}\right)=10 \mathrm{~T}_{\mathrm{H}} \\ \text { no heating }\end{array} \\ \begin{array}{c}\mathrm{T}\left(\mathrm{He}^{++}\right)=\mathrm{T}_{\mathrm{H}} / 10 \\ \text { bulk }\end{array} & & \end{array}$


(Fig. 4). We find that the heating is continued until the ions reach the boundary of the $p=2$ cell for the $n=3$ resonance; this boundary is indicated by the vertical line $V_{\perp}=12.5 a\left(\mathrm{He}^{++}\right)$. Only a few ions cross this limit. Table 1 shows that the threshold criterion for stochastic acceleration is met up to the $p=2$ cell for both the $\mathrm{n}=2$ and 3 resonances.

\section{Summary}

We have demonstrated numerically that ionospheric ions, such as $\mathrm{He}^{+}, \mathrm{He}^{++}$and $\mathrm{O}^{+}$, can be accelerated stochastically by a coherent EHC wave with parameters typical of the auroral plasma at altitudes greater than one earth radius, where such waves have been detected in association with ion beams (Kintner et al, 1979). One of the main assumptions in our study was that the heavy ions were minor constituents, so that their acceleration did not affect the wave. The most significant contribution of this study was to indicate the conditions under which the acceleration takes place. We also noted that the initial ion temperature is an important factor in determining whether the acceleration occurs at all and if it occurs whether it leads to an energetic tail or to bulk heating.

We found that the $\mathrm{O}^{+}$ions are heated only when their initial temperature satisfies the condition, $\mathrm{T}\left(\mathrm{O}^{+}\right) \geqslant \mathrm{T}_{\mathrm{H}}$. On the other hand, $\mathrm{He}^{+}$and $\mathrm{He}^{++}$are accelerated even when they are initially very cold. Table 3 summarizes the initial temperature dependence of the heating for the different ion species. The reason for this basic difference is that only the $\mathrm{O}^{+}$ions which have an initial perpendicular velocity $V_{\perp} \geqslant\left(1-\alpha^{1 / 2} / \mathbf{n}\right) \omega / \mathbf{k}_{\perp}$ undergo acceleration, while for the relatively lighter ions, such as $\mathrm{He}^{+}$and $\mathrm{He}^{++}$, cyclotron resonance is the dominant determining factor for the ions undergoing acceleration. Therefore, the dominant heating mechanism for $\mathrm{O}^{+}$is nonresonant stochastic acceleration, while for the light ions cyclotron resonant stochastic heating dominates (Abe et al, 1980).

To our knowledge the only experimental information available on the thermal structure of the high-latitude topside ionosphere derives from the satellite observations of Maier and Hoffman (1974), which can be interpreted as showing different $\mathrm{O}^{+}$and $\mathrm{H}^{+}$ temperatures. The measured $\mathrm{H}^{+} / \mathrm{O}^{+}$temperature ratio varied from 1 to 10 , with $\mathrm{H}^{+}$typically $2-3$ times hotter than $\mathrm{O}^{+}$. Therefore, some preheating mechanism must be operative for the proposed stochastic acceleration mechanism to account for $\mathrm{O}^{+}$observations. With regard to $\mathrm{He}^{+}$and $\mathrm{He}^{++}$, no temperature measurements are currently available. However, theoretical calculations by Raitt et al (1978) indicate that these ions should have a temperature that is comparable to or lower than the $\mathrm{H}^{+}$ temperature. Consequently, $\mathrm{He}^{+}$and $\mathrm{He}^{++}$should be stochastically accelerated by $\mathrm{EHC}$ waves.

In this study our emphasis has been on the heating mechanism. The effect of the inhomogeneity of the geomagnetic field has not been taken into account. Our calculations show that the time required for the heating $(<2 \mathrm{sec})$ is shorter than the time it takes for the ions to be convected out of the heated region owing to the inhomogeneity in the geomagnetic field.

Finally, we note that we have done a comprehensive study of the parametric dependence of the heating rates on the ion charge, mass, and initial temperature as well as on the wave parameters (amplitude, $\mathbf{k}_{\perp} / \mathbf{k}_{\|}, \mathbf{k}_{\perp} \mathbf{r}_{\mathrm{H}}$ ). These results will be reported elsewhere.

Acknowledgement. This research was supported by NASA grant NAGW-77 and NSF grant ATM-8015497 to Utah State University.

\section{References}

Abe, H., H. Momota, and R. Itatani, High-energy tail formation by a monochromatic wave in a magnetized plasma, Phys. Fluids, 23, 2417,1980 .

Fakuyama, A., H. Momota, and R. Itatani, Stochastic acceleration by an electrostatic wave near ion cyclotron harmonics, Phys. Rev. Lett., $38,701,1977$.

Holzer, T. E., J. A. Fedder and P. M. Banks, A comparison of kinetic and hydrodynamic models of an expanding ion-exosphere, J. Geophys. Res., 76, 2453, 1971.

Karney, C. F. F., Stochastic ion heating by a lower hybrid wave, Phys. Fluids, 21, 1584, 1978.

Kindel, J. M. and C. F. Kennel, Topside current instabilities, J. Geophys. Res., 76, 3055, 1971.

Kintner, P. M., M. C. Kelley, and F. S. Mozer, Electrostatic hydrogen cyclotron waves near one earth radius altitude in the polar magnetosphere, Geophys. Res. Lett., 5, 139, 1978.

Kintner, P. M., M. C. Kelley, R. D. Sharp, A. G. Ghielmetti, M. Temerin, C. Cattell, P. F. Mizera, and J. F. Fennell, Simultaneous observations of energetic $(\mathrm{keV})$ upstreaming ions and electrostatic hydrogen cyclotron waves, J. Geophys. Res., 84, 7201, 1979.

Klumpar, D. M., Transversely accelerated ions: an ionospheric source of hot magnetospheric ions, J. Geophys. Res., 84, 4229, 1979.

Lysak, R. L., M. K. Hudson, and M. Temerin, Ion heating by strong electrostatic ion cyclotron turbulence, J. Geophys. Res., 85, 678, 1980.

Maier, E. J. and J. H. Hoffman, Observation of a two-temperature ion energy distribution in regions of polar wind flow, J. Geophys. Res., 79, 2444-2447, 1974.

Papadopoulos, K., J. D. Gaffey, Jr. and P. J. Palmadesso, Stochastic acceleration of large $M / Q$ ions by hydrogen cyclotron waves in the magnetosphere, Geophys. Res. Lett., 7, 1014, 1980.

Raitt, W. J., R. W. Schunk and P. M. Banks, A comparison of the temperature and density structure in high and low speed thermal proton flows, Planet. Space Sci., 23, 1103-1117, 1975.

Raitt, W. J., R. W. Schunk and P. M. Banks, The influence of convection electric fields on thermal proton outflow from the ionosphere, Planet. Space Sci., 25, 291-301, 1977.

Raitt, W. J., R. W. Schunk and P. M. Banks, Helium ion outflow from the terrestrial ionosphere, Planet. Space $\underline{\text { Sci., }} \underline{26}, 255-268$, 1978.

Smith, G. R. and A. N. Kaufman, Stochastic acceleration by an obliquely propagating wave-an example of overlapping resonances, Phys. Fluids, 21, 2230, 1978.

Ungstrup, E., D. M. Klumpar, and W. J. Heikkila, Heating of ions to superthermal energies in the topside ionosphere by electrostatic ion cyclotron waves, J. Geophys. Res., 84, 4289, 1979.

(Received Ju1y 29, 1981; accepted October 2, 1981.) 